\title{
Analisis Kebutuhan Parkir pada Dinas Pengelolaan Sumber Daya Air Provinsi Lampung
}

\section{Analysis of Parking Needs at the Water Resources Management Office of Lampung Province}

\author{
Fery Hendi Jaya $^{1^{*}}$, Ari Fermana ${ }^{1}$ \\ ${ }^{1}$ Program Studi Teknik Sipil Fakultas Teknik Universitas Sang Bumi Ruwa Jurai \\ Email:feryhjaya@gmail.com
}

\begin{abstract}
Abstrak
Transportasi merupakan bagian integral dari banyak kegiatan sosial dan ekonomi, sehingga pelayanan transportasi dengan kualitas dan kapasitas yang cukup dapat diandalkan. Salah satu pelayanan transportasi adalah layanan parkir. Tujuan penelitian ini yaitu untukmemberikan rekomendasi arah kebijakan bagi pengambil keputusan atas dasar hasil studi dengan sasaran pengaturan ruang parkir yang ada di Dinas PSDA Provinsi Lampung agar lebih efisien dan maksimal dalam penempatan kendaraan, serta untuk menganalisis kapasitas dan kebutuhan (Demand) ruang parkir di Dinas PSDA Provinsi Lampung. Ruang parkir yang berada di Dinas Pengelolaan Sumber Daya Air (PSDA) Provinsi Lampung terletak di bagian depan gedung utama dan bagian samping Dinas PSDA Provinsi Lampung yang diperuntukan untuk pegawai. Kapasitas ruang parkir yang tersedia yaitu seluas $750 \mathrm{~m} 2$ untuk kendaraan mobil dan $120 \mathrm{~m} 2$ untuk kendaraan motor. Dari perhitungan data exisiting dan optimasi dengan mengambil sampel tiga hari yaitu pada tanggal 5 April 2021, 7 April 2021 dan 9 April 2021 diperoleh tingkat pergantian parkir harian (parking turn over) dimana hasil perhitungan optimasi lebih baik dari kondisi existing. Perhitungan Indeks Parkir (IP), untuk kendaraan mobil pada kondisi optimasi memiliki hasil persentase yang lebih baik dibandingkan dengan kondisi existing pada Satuan Ruang Parkir (SRP) sudut kemiringan $90^{\circ}$. Penelitian ini merekomendasikan kepada pihak terkait agar menggunakan sistem parkir dengan SRP $90^{\circ}$ sehingga ruang parkir yang ada bisa digunakan secara optimal.
\end{abstract}

Kata kunci: Parkir, Kapasitas Parkir, Indeks Parkir, SRP

Abstract

Transportation is an integral part of many social and economic activities, so that transportation services with sufficient quality and capacity can be relied on. One of the transportation services is parking service. The purpose of this study is to provide recommendations for policy directions for decision makers on the basis of the results of the study with the aim of regulating parking spaces at the PSDA Office of Lampung Province to be more efficient and maximal in vehicle placement, as well as to analyze the capacity and demand (Demand) of parking spaces at the PSDA Office. Lampung province. The parking space at the Lampung Province Water Resources Management Agency (PSDA) is located in front of the main building and the side of the Lampung Province PSDA Office which is intended for employees. The available parking space capacity is $750 \mathrm{~m} 2$ for cars and $120 \mathrm{~m} 2$ for motorcycles. From the calculation of existing data and optimization by taking a three-day sample, namely on April 5, 2021, April 72021 and April 9, 2021, the daily parking turnover rate (parking turn over) is obtained where the results of the optimization calculation are better than the existing conditions. The calculation of the Parking Index (IP), for cars under optimization conditions has a better percentage result compared to the existing conditions in the Parking Space Unit (SRP) with a $90^{\circ}$ angle of inclination. This study recommends to related parties to use a parking system with an SRP of $90^{\circ}$ so that the existing parking spaces can be used optimally.

Keywords: Parking, Parking Capacity, Parking Index, SRP 


\section{PENDAHULUAN}

Perpindahan barang atau orang dari satu tempat ke tempat lain dengan berbagai cara dan alat yang digunakan untuk mencapai perpindahan tersebut. Pertumbuhan kemampuan dan kebutuhan untuk mengangkut barang dalam jumlah besar atau sejumlah besar orang dalam jarak yang jauh dengan kecepatan tinggi dalam kenyamanan dan keamanan telah menjadi indeks peradaban dan khususnya kemajuan teknologi. Perjalanan atau pergerakan orang, barang atau jasa yang dimaksudkan untuk berpindah dari suatu tempat ke tempat lain untuk memenuhi kebutuhan manusia itulah yang sekarang ini lebih dikenal dengan istilah transportasi [1].

Pada banyak hal transportasi adalah bagian integral dari banyak kegiatan sosial dan ekonomi, sehingga sangat penting artinya pelayanan transportasi dengan kualitas dan kapasitas yang cukup dapat diandalkan. Salah satu pelayanan transportasi adalah layanan parkir. Dengan adanya peningkatan taraf hidup masyarakat di Indonesia khususnya di Kota Bandar Lampung, penggunaan sarana transportasipun sangat penting gunanya dalam mencapai suatu lokasi tujuan. Maka akan diperlukan suatu sistem pengaturan parkir yang efektif dan efisien [2].

Dinas Pengelolaan Sumber Daya Air (PSDA) Provinsi Lampung yang berada di Kota Bandar Lampung adalah Dinas yang dibawahi oleh Pemerintah Provinsi Lampung, Kota Bandar Lampung, penggunaan sarana transportasi pribadi semakin banyak, dengan banyaknya penggunaan kendaraan pribadi maka tempat parkir dalam hal ini bergerak di bidang Pekerjaan Umum Khusus Pengairan. Dinas PSDA Provinsi Lampung saat ini mempunyai permasalahan keterbatasan lahan fasilias parkir yang tersedia, sehingga mengganggu mobilitas kegiatan di halaman dinas tersebut. Keterbatasan lahan fasilitas parkir ini menimbulkan permasalahan terhadap pegawai yang membawa kendaraan dan tamu yang akan menggunakan lahan parkir.

Kebutuhan area kegiatan parkir berbeda antara tempat satu dan lainnya, hal ini tergantung kepada pelayanan, tarif yang diberlakukan, ketersediaan ruang parkir, tingkat pemilikan kendaraan, dan tingkat pendapatan masyarakat. Satuan Ruang Parkir (SRP) adalah luas efektif untuk memarkir satu kendaraan termasuk ruang bebas dan bukaan pintu. Untuk menentukan Satuan Ruang Parkir didasarkan faktor-faktor antara lain standar dimensi untuk kendaraan mobil penumpang, ruang bebas parkir dan lebar bukaan pintu kendaraan. Ruang bebas parkir terdiri dari dua arah yaitu arah lateral dan arah longitudinal kendaraan. Arah lateral ditetapkan pada saat pintu kendaraan dibuka, yang diukur dari ujung pintu terluar ke badan kendaraan parkir yang ada di sampingnya [3].

Ruang ini diberikan agar tidak terjadi benturan antara pintu kendaraan dengan kendaraan lainnya pada saat penumpang membuka pintu kendaraan. Arah longitudinal diberikan di depan kendaraan untuk menghindari benturan dengan dinding atau kendaraan yang lewat pada jalur gang, jarak dari arah lateral diambil sebesar $5 \mathrm{~cm}$ dan untuk jarak longitudinal sebesar $30 \mathrm{~cm}$.

Salah satu masalah yang akan dievaluasi adalah memberikan rekomendasi arah kebijakan bagi pengambil keputusan atas dasar hasil studi dengan sasaran pengaturan ruang parkir yang ada di Dinas PSDA Provinsi Lampung agar lebih efisien dan maksimal dalam penempatan kendaraan, serta untuk menganalisis kapasitas dan kebutuhan (Demand) ruang parkir di Dinas PSDA Provinsi Lampung.

Dalam penelitian ini terhadap 
penggunaan lahan parkir di Dinas PSDA Provinsi Lampung digunakan beberapa parameter. Parameter tersebut digunakan dalam porses analisa yang hasilnya dapat digunakan sebagai dasar dalam pengambilan kesimpulan dalam penelitian ini. Parameter tersebut antara lain akumulasi jumlah kendaraan parkir, indeks kendaraan parkir, dan kapasitas parkir [4] .

Novier, dkk melakukan penelitian mengenai analisis kebutiuhan ruang parker Paragon Mall Semarang. Tahapan yang dilakukan meliputi: perhitungan kapasitas standar parkir, perhitungan kebutuhan parkir saat ini dengan selisih grafik kumulatif, optimasi ruang dan tarif, serta prediksi masa depan. Dari hasil pembahasan diketahui optimasi ruang akan meningkatkan kapasitas lahan parkir Mobil Merbabu menjadi 145 SRP (total menjadi 1115 SRP) dan lahan parkir Sepeda motor Wika 1272 SRP (total menjadi 2030 SRP), penambahan marka parkir diperlukan pada lahan parkir non-gedung, optimasi pentarifan didapatkan hasil rekomendasi [5].

Messah, dkk juga melakukan penelitian mengenai Analisis Kebutuhan Lahan Parkir di Rumahn Sakit Umum Prof. DR. W.Z. Johannes Kupang. Metode yang diterapkan dalam penelitian ini adalah dengan melakukan survey langsung di lapangan untuk mendapatkan jumlah kendaraan yang parkir yaitu dengan mencatat plat nomor kendaraan yang masuk dan keluar. Data kendaraan parkir tersebut kemudian dianalisis dengan menggunakan analisa regresi untuk mengetahui variabel yang berpengaruh terhadap kebutuhan ruang parkir dan berdasarkan luas lantai bangunan. Berdasarkan perhitungan kebutuhan parkir dan luas lahan parkir diperoleh total kebutuhan luas parkir untuk kendaraan roda dua adalah $747 \mathrm{~m}^{2}$ dengan jumlah parkir sebanyak 498 petak dan luas total kebutuhan lahan parkir untuk kendaraan roda empat adalah $250 \mathrm{~m}^{2}$ dengan jumlah petak parkir sebesar 20 petak. Model parkir yang direkomendasikan untuk kendaraan roda dua yaitu $90^{\circ}$ dan model parkir untuk kendaraan roda empat yaitu $90^{\circ}[6]$.

\section{METODE PENELITIAN}

Substansi dari penelitian ini adalah melakukan analisa kebutuhan parkir di Dinas Pengelolaan Sumber Daya Air (PSDA Provinsi Lampung, dengan melakukan analisa berdasarkan parameter akumulasi jumlah kendaraan parkir, indeks kendaraan parkir, dan kapasitas parkir.

Teknik pengumpulan data untuk setiap penelitian sangat diperlukan agar mempermudah dalam pengambilan data maupun pengolahan data. Data yang dibutuhkan diperoleh melalui dua jenis data yaitu data primer dan data sekunder.

Data primer merupakan data yang diperoleh secara langsung melalui kegiatan survey di lapangan. Adapun data primer yang dibutuhkan pada studi ini adalah :

1. Layout pelataran parkir Dinas PSDA

Provinsi Lampung; dan

2. Jumlah pegawai pengguna parkir.

Untuk data primer, pengumpulan data dilaksanakan pada hari dan periode pengamatan yang ditetapksan dengan mempertimbangkan penentuan waktu survey berdasarkan peak day, yakni dimana waktu survey dipilih satu hari atau lebih dari jumlah hari dalam satu minggu yang merupakan hari terpadat pada minggu itu yang mewakili seluruh hari dalam satu minggu, satu bulan, bahkan dalam satu tahun.

Penentuan peakday biasanya dibagi dalam 3 (tiga) waktu, yaitu early week, midweek, dan weekend. Untuk early week biasanya dipilih hari senin atau selasa, untuk midweek dipilih hari rabu atau kamis, sedangkan untuk weekend dipilih hari jum'at, sabtu, dan minggu. Pada penelitian ini diambil 2 (dua) hari dalam 
satu minggu dimana hari tersebut mewakili hari-hari yang ramai dikunjungi masyarakat.

Data sekunder diperoleh dari studi dokumentasi pada instansi yang bersangkutan. Data sekunder diperlukan untuk mengetahui sistem operasional parkir. Untuk maksud tersebut, data yang diperlukan antara lain:

1. Jumlah kendaraan parkir dan kapasitas parkir pada wilayah studi area parkir;

2. Data kelengkapan sarana dan fasilitas parkir di Dinas PSDA Provinsi Lampung yang meliputi rambu, marka dan bangunan pelengkap.

\section{Analisis Data}

Data kendaraan yang diperoleh dihitung selisih waktu masuk dan waktu keluar dari masing - masing kendaraan sehingga diperoleh lama kendaraan melakukan parkir. Apabila hasil selisih yang diperoleh lebih kecil dari lima menit maka kendaraan dianggap tidak parkir. Setelah diperoleh selisih waktu masuk dan keluar kendaraan, dihitung jumlah kendaraan yang parkir setiap jam sehingga akan diperoleh akumulasi kendaraan parkir, yang dihitung berdasarkan persamaan 1 [1].

Akumulasi $=Q_{\text {in }}-Q_{\text {out }}+Q_{s}$

Dimana,

$Q_{\text {in }} \quad$ : Kendaraan masuk lokasi parkir

Qout : Kendaraan keluar lokasi parkir

$\mathrm{Q}_{\mathrm{s}} \quad$ : Kendaraan yang telah berada di

Lokasi parkir sebelum dilakukan pengamatan

Akumulasi kendaraan parkir setiap jam dibagi dengan jumlah ruang parkir yang tersedia akan menghasilkan indeks parkir (IP), yang dihitung berdasarkan persamaan 2 [7].

$$
I P=\frac{(\text { Akumulasi } \times 100 \%)}{\text { Petak Parkir Tersedia }}
$$

Dari data waktu kendaraan yang diperoleh dihitung selisih waktu kendaraan masuk dan waktu kendaraan keluar masing- masing kendaraan sehingga akan diperoleh lama kendaraan melakukan parkir/durasi parker, yang dihitung berdasarkan persamaan 3 [7].

Durasi Parkir $=T_{\text {out }}-T_{\text {in }}$

Dimana,

$\mathrm{T}_{\text {in }}$ : waktu kendaraan masuk lokasi parkir $\mathrm{T}_{\text {out }}$ : waktu kendaraan keluar lokasi parkir

Untuk mendapatkan nilai Parking Turn Over (PTO) dengan membagi jumlah ruang parkir (petak parkir) yang dihitung berdasarkan persamaan 4 [7].

Parking Turn Over (PTO) :

Petak $\frac{\mathrm{Q}_{\mathrm{p}}}{\text { Parkir Tersedia }}$

Dimana,

$\mathrm{Q}_{\mathrm{p}}$ : Jumlah kendaraan yang parkir/periode waktu tertentu.

Dari gambaran permasalahan yang dikemukakan, metodologi yang digunakan dan data-data yang diperoleh, maka dari penelitian ini diharapkan memperoleh solusi dari masalah parkir di Dinas Pengelolaan Sumber Daya Air Provinsi Lampung dengan mengoptimalisasikan lahan parkir yang tersedia dan membuat skema ulang penempatan kendaraan pada lahan parkir yang efektif dan efisien.

\section{HASIL DAN PEMBAHASAN}

\section{Data Pelataran Parkir}

Ruang parkir yang berada di Dinas Pengelolaan Sumber Daya (PSDA) Air Provinsi Lampung yang berupa tempat parkir terletak di bagian depan gedung utama dan bagian samping Dinas PSDA 
Provinsi Lampung yang diperuntukan untuk pegawai. Kapasitas ruang parkir yang tersedia yaitu seluas $750 \mathrm{~m} 2$ untuk kendaraan mobil dan $120 \mathrm{~m} 2$ untuk kendaraan motor.

Dalam perhitungannya luas ruang parkir kendaran bermotor dan luas ruang parkir kendaraan mobil dipisahkan karena hal tersebut sudah menjadi aturan di Dinas terkait. Dari ruang parkir yang tersedia banyak kendaraan yang masih memakirkan kendaraan tidak beraturan dikarenakan pada tempat parker yang tersedia belum memiliki aturan petak parkir, sehingga para pengunjung memarkirkan kendaraanya melihat kondisi dimana ada yang terlihat kosong disitupun mereka akan memarkirkan kendaraanya.

Sehingga mengakibatkan tidak tercukupinya lahan parkir yang tersedia, terutama pada jam-jam sibuk. Pada penelitian ini lahan parkir yang tersedia dibagi menjadi menjadi beberapa zona, hal tersebut dikarenakan tempat parkir yang terpisah.

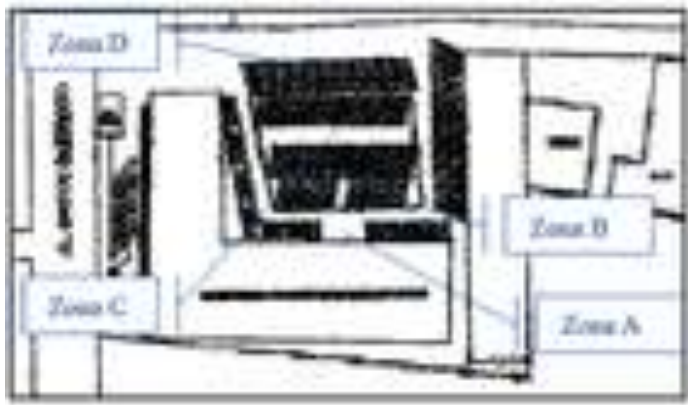

Gambar 1. Layout dan Pembagian Zona Parkir

Pada Gambar 1 di jelaskan bahwa terdapat 4 zona untuk parkir kendaraan mobil yaitu zona $\mathrm{A}, \mathrm{B}, \mathrm{C}$ dan $\mathrm{D}$. Pengambilan data parkir sendiri berjumlah tiga hari kerja yaitu tanggal 5 April 2021, 7 April 2021 dan 9 April 2021.

\section{Jumlah Kendaraan Parkir}

Perhitungan jumlah parkir dengan memperhitungkan jumlah kendaraan parkir yang ada pada tanggal penelitian yang telah ditentukan. Perhitungan jumlah kendaraan parkir ini sangat diperlukan untuk mengetahui indeks parkir pada lahan parkir yang ada. Penelitian ini tidak memperhitungkan akumulasi parkir, karena kendaraan parkir memiliki tipe menetap.

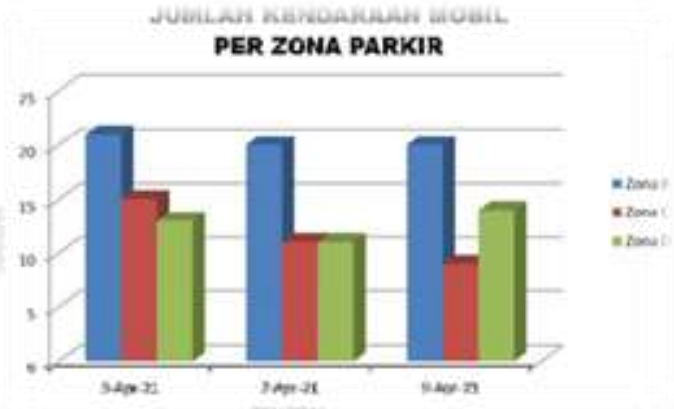

Gambar 2. Diagram jumlah kendaraan parkir mobil di setiap zona

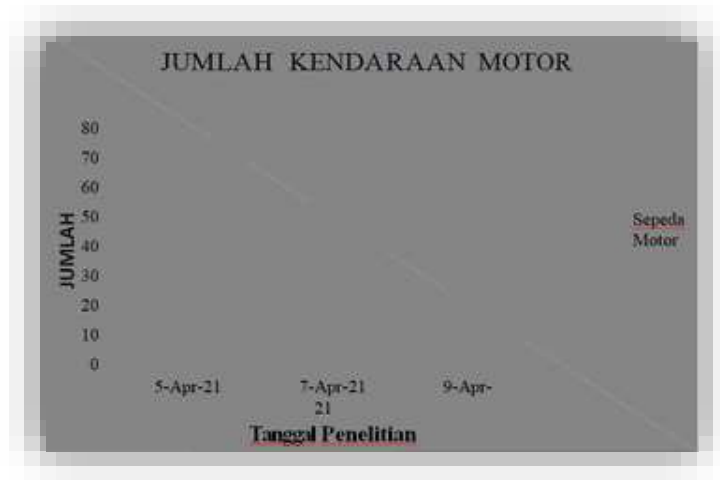

Gambar 3. Diagram jumlah kendaraan parkir sepeda motor

\section{Parking Turn Over}

Parking Turn Over adalah tingkat pemakaian satu ruang parkir yaitu jumlah kendaraan yang menggunakan ruang yang sama pada suatu periode waktu. Tingkat pemakaian ruang parkir ini tidak sama untuk semua ruang parkir yang ada. Untuk melihat tingkat peningkatan setiap ruang parkir dibutuhkan data yang lebih lengkap, namun secara keseluruhan tingkat pemakaian ruang parkir dapat dihitung dengan membagi jumlah total kendaraan parkir dalam sehari dengan jumlah ruang parkir yang tersedia. Di dalam penelitian ini menghitung Parking Turn Over di setiap zona. Pada perhitungan Parking 
Turn Over ini diperhitungkan dua metode yaitu existing dan simulasi. Untuk kapasitas ruang parkir existing adalah 18 ruang parkir mobil pada Zona B.

Sebelas ruang parkir mobil pada Zona $\mathrm{C}$, Sebelas ruang parkir mobil untuk Zona D dan enam puluh empat ruang parkir untuk kendaraan sepeda motor. Adapun kapasitas ruang yang telah dibuat sesuai dengan satuan ruang parkir yaitu dengan sudut kemiringan $60^{\circ}$ dan $90^{\circ}$ untuk kendaraan mobil dan $90^{\circ}$ untuk kendaraan mobil. Berikut adalah perhitungan Parking Turn Over:

Tabel. 1. Parking Turn Over kendaraan mobil kondisi existing Zona B

\begin{tabular}{|c|c|c|c|c|}
\hline No & Tanggal & $\begin{array}{c}\text { Jumlah Kendaraan } \\
\text { Molvil (Zona B) }\end{array}$ & SRP & $\begin{array}{c}\text { Parking } \\
\text { Tun Over }\end{array}$ \\
\hline 1 & $5-A p r-21$ & 21 & 18 & 1.17 \\
\hline 2 & $7 \cdot$ Apr-21 & 20 & 18 & 1.11 \\
\hline 3 & $9 \cdot$ Apr-21 & 20 & 18 & 1.11 \\
\hline
\end{tabular}

Tabel. 2. Parking Turn Over kendaraan mobil kondisi existing Zona $\mathrm{C}$

\begin{tabular}{|c|c|c|c|c|}
\hline No & Tanggal & $\begin{array}{c}\text { Jumbah Kendaraan } \\
\text { Mobil (Zona C) }\end{array}$ & SRP & $\begin{array}{c}\text { Parking } \\
\text { Tum Over }\end{array}$ \\
\hline 1 & 5 -Apr-21 & 15 & 11 & 1.36 \\
\hline 2 & 7 -Apr-21 & 11 & 11 & 1.00 \\
\hline 3 & 9 -Apr-21 & 9 & 11 & 0.82 \\
\hline
\end{tabular}

Tabel. 3. Parking Turn Over kendaraan mobil kondisi existing Zona D

\begin{tabular}{|c|c|c|c|c|}
\hline No & Tanggal & $\begin{array}{c}\text { Jumbah Kendaraan } \\
\text { Mobil (Zona D) }\end{array}$ & SRP & $\begin{array}{c}\text { Paking } \\
\text { Tum Over }\end{array}$ \\
\hline 1 & $5-A p r-21$ & 13 & 11 & 1.18 \\
\hline 2 & $7-A p r-21$ & 11 & 11 & 1.00 \\
\hline 3 & $9-A p r-21$ & 14 & 11 & 1.27 \\
\hline Sumber: hasil samey dan periutungal &
\end{tabular}

Tabel. 4. Parking Turn Over kendaraan mobil kondisi existing

\begin{tabular}{|c|c|c|c|c|}
\hline No & Tanggal & $\begin{array}{c}\text { Jumlah Kendaraan } \\
\text { Motor }\end{array}$ & SRP & $\begin{array}{c}\text { Parking } \\
\text { Turn Over }\end{array}$ \\
\hline 1 & $5-A p r-21$ & 73 & 64 & 1.14 \\
\hline 2 & $7-A p r-21$ & 70 & 64 & 1.09 \\
\hline 3 & $9-A p r-21$ & 56 & 64 & 0.88 \\
\hline
\end{tabular}

Tingkat pergantian parkir harian (Parking Turn Over) kondisi existing, untuk hari pertama kendaraan mobil pada Zona B sebesar 1,17 mobil/petak, Zona C sebesar 1,36 mobil/petak, Zona D sebesar 1,18 mobil/petak parkir dan untuk motor sebesar 1,14 motor/petak parkir. Untuk hari kedua kendaraan mobil pada Zona B sebesar 1,11 mobil/petak, Zona C sebesar 1,0 mobil/petak, Zona D sebesar 1,0 mobil/petak parker dan untuk sepeda motor sebesar 1,09 motor/petak parkir. Pada hari ketiga kendaraan mobil pada Zona B sebesar 1,11 mobil/petak, Zona C sebesar 0,82 mobil/petak, Zona D sebesar 1,27 mobil/petak parkir dan untuk motor sebesar 0,88 motor/petak parkir.

Tabel. 5. Parking Turn Over Kendaraan Mobil Optimasi Zona B

\begin{tabular}{|c|c|c|c|c|c|c|}
\hline No & Tanggal & $\begin{array}{c}\text { Jumblah } \\
\text { Kendaraan } \\
\text { Mobil (Zona } \\
\text { B) }\end{array}$ & $\begin{array}{l}\text { SRP } \\
60\end{array}$ & $\begin{array}{l}\text { Parking } \\
\text { Tum } \\
\text { Ovfr }\end{array}$ & $\begin{array}{l}\text { SRP } \\
90\end{array}$ & $\begin{array}{l}\text { Patking } \\
\text { Tum } \\
\text { Over }\end{array}$ \\
\hline 1 & S-Apr-21 & 21 & 20 & 1.05 & 24 & 0.88 \\
\hline 2 & $7 \cdot$ Apr -21 & 20 & 20 & 1.00 & 24 & 0.83 \\
\hline 3 & 9-Apr-21 & 20 & 20 & 1.00 & 24 & 0.83 \\
\hline
\end{tabular}

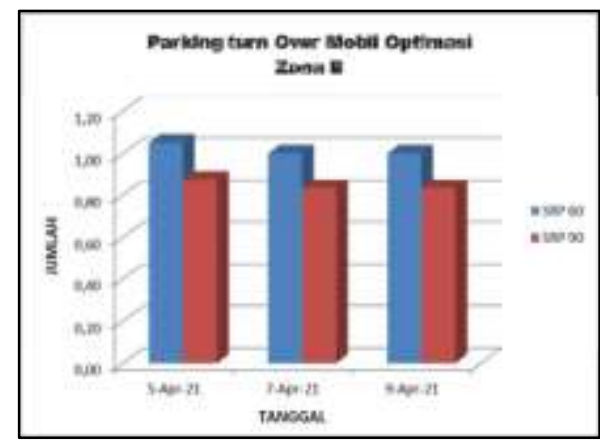

Gambar 4. Parking Turn Over Optimasi Zona B

Tabel. 6. Parking Turn Over Kendaraan Mobil Optimasi Zona C

\begin{tabular}{|c|c|c|c|c|c|c|}
\hline So & Inatal & $\begin{array}{c}\text { Jublah } \\
\text { Kendaras } \\
\text { Alotel (2osic) }\end{array}$ & $\begin{array}{l}\text { SRP } \\
\text { \& }\end{array}$ & $\begin{array}{l}\text { Parkat } \\
\text { Ters } \\
\text { Oww }\end{array}$ & $\begin{array}{l}5,0 \\
90\end{array}$ & $\begin{array}{l}\text { Parting } \\
\text { Tarn } \\
\text { Orer }\end{array}$ \\
\hline 1 & 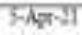 & 15 & T5 & 175 & 36 & Dद्य \\
\hline 2 & $7 x{ }^{2}-21$ & TI & TI & 685 & 96 & वका \\
\hline 3 & $9.4 \div-21$ & 9 & ib & 20 & 10 & 250 \\
\hline
\end{tabular}




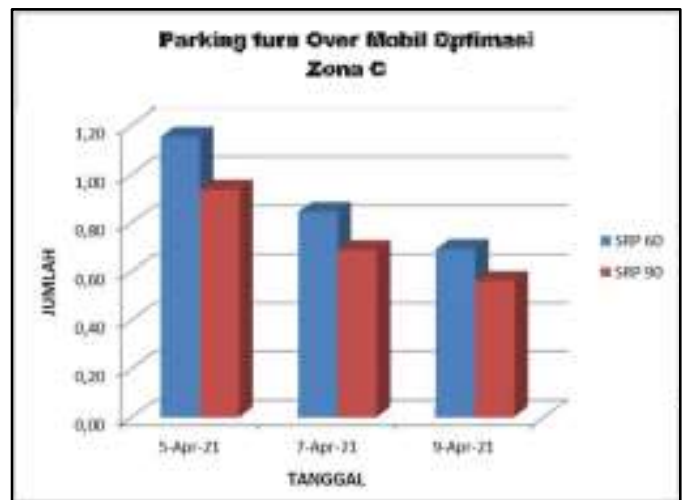

Gambar 5. Parking Turn Over Optimasi Zona C

Tabel 7. Parking Turn Over Kendaraan Mobil Optimasi Zona D

\begin{tabular}{|c|c|c|c|c|c|c|}
\hline No & Tangal & $\begin{array}{c}\text { Jumlah } \\
\text { Kendaraan } \\
\text { Mobil (Zona } \\
\text { D) }\end{array}$ & $\begin{array}{l}\text { SRP } \\
60\end{array}$ & $\begin{array}{l}\text { Parking } \\
\text { Tum } \\
\text { Over }\end{array}$ & $\begin{array}{l}\text { SRP } \\
90\end{array}$ & $\begin{array}{l}\text { Pakking } \\
\text { Tun } \\
\text { Over }\end{array}$ \\
\hline 1 & 5.Apr-21 & 13 & 13 & 1.00 & 16 & 0.81 \\
\hline 2 & 7.Apr-21 & 11 & 13 & 0.85 & 16 & 0,69 \\
\hline 3 & 9-Apr-2I & 14 & 13 & 1.08 & 16 & 0.88 \\
\hline
\end{tabular}

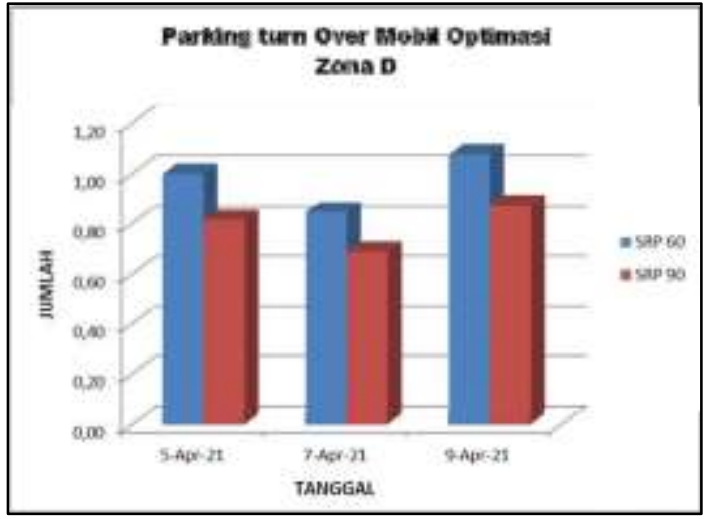

Gambar 6. Parking Turn Over Optimasi Zona D

Tabel. 8. Parking Turn Over Kendaraan Sepeda Motor

\begin{tabular}{|c|c|c|c|c|}
\hline No & Tansgal & $\begin{array}{c}\text { Jumbli } \\
\text { Kendaraa } \\
\text { n Motor }\end{array}$ & SRP & $\begin{array}{l}\text { Pathing } \\
\text { Turn } \\
\text { Over }\end{array}$ \\
\hline 1 & $5 \cdot A p r-21$ & 73 & 85 & 0.86 \\
\hline 2 & $7 \cdot$ Apr-21 & 70 & 85 & 0.82 \\
\hline 3 & $9 \cdot A p r-21$ & 56 & 85 & 0.66 \\
\hline
\end{tabular}

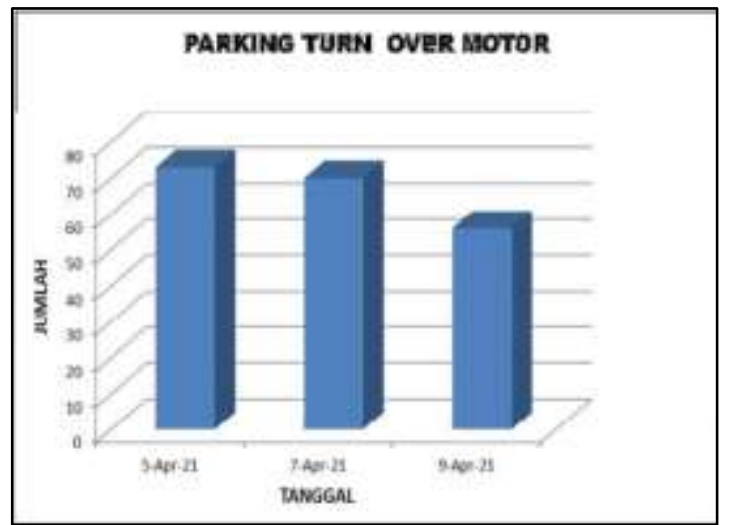

Gambar 7. Parking Turn Over Optimasi Sepeda Motor

Tingkat pergantian parkir harian (Parking Turn Over), untuk perhitungan sesuai SRP pada hari pertama kendaraan mobil pada zona $\mathrm{B}, \mathrm{C}$ dan $\mathrm{D}$ dengan sudut $60^{\circ}$ sebesar 1,05 mobil/petak parkir 1,15 mobil/petak parkir dan 1,00 mobil/petak parkir. Untuk sudut kemiringan $90^{\circ}$ sebesar 0,88 mobil/petak parkir, 0,94 mobil/petak parkir dan $0,81 \mathrm{mobil} /$ petak parkir. Untuk hari kedua pada sudut $60^{\circ}$ sebesar 1,00 mobil/petak parkir 0,85 mobil/petak parkir dan 0,89 mobil/petak parker.

Untuk sudut kemiringan $90^{\circ}$ sebesar 0,83 mobil/petak parkir, 0,69 mobil/petak parkir dan 0,69 mobil/petak parkir. Untuk hari ketiga pada sudut $60^{\circ}$ sebesar 1,00 mobil/petak parkir, 0,69 mobil/petak parkir dan 1,08 mobil/petak parkir. Untuk sudut kemiringan $90^{\circ}$ sebesar 0,83 mobil/petak parkir, 0,56 mobil/petak parkir dan 0,88 mobil/petak parkir.

Dari hasil perhitungan Parking Turn Over Mobil diatas didapatkan perbandingan antara Parking Turn Over kondisi existing dengan kondisi optimasi dimana Parking Turn Over pada kondisi optimasi lebih kecil dari pada kondisi existing. Hal ini karena petak ruang parkir pada kondisi optimasi lebih banyak dari kondisi existing. Untuk kendaraan motor sendiri dengan kondisi optimasi memiliki nila Parking Turn Over berturut-turut selama tiga hari adalah 0,86 motor/petak parkir, 0,82 motor/ petak parkir dan 0,66 motor/petak parkir. 
Jurnal Teknika Sains

Volume 06, Nomor 02, 2021

Perbandingan antara Parking Turn Over kondisi existing pada parkir sepeda motor dengan kondisi optimasi dimana Parking Turn Over pada kondisi optimasi lebih kecil dari pada kondisi existing.

\section{Indeks Parkir (IP)}

Indeks parkir adalah jumlah kendaraan yang parkir dibagi dengan jumlah petak parkir yang tersedia, dinyatakan dalam persentase [8]. Di dalam penelitian ini terdapat dua perhitungan indeks parkir, dimana perhitungan tersebut adalah menghitung indeks parkir dengan menggunakan data kapasitas ruang parkir existing dan indeks dengan menggunakan data kapasitas ruang yang telah dibuat sesuai dengan satuan ruang parkir yaitu dengan sudut kemiringan $60^{\circ}$ dan $90^{\circ}$. Adapun kapasitas ruang parkir existing adalah 18 ruang parkir untuk Zona $\mathrm{B}, 11$ ruang parkir pada zona $\mathrm{C}$ dan 11 ruang parkir pada zona D. untuk kendaraan motor sendiri berjumlah 64 ruang parkir.

Sedangkan kapasitas ruang parkir yang sesuai Satuan Ruang Parkir yang dioptimasi adalah pada sudut kemiringan $60^{\circ}$ berjumlah 20 ruang parkir pada Zona B, 13 ruang parkir pada Zona $\mathrm{C}, 13$ dan ruang parkir pada Zona D. Untuk sudut kemiringan $90^{\circ}$ berjumlah 24 ruang parkir pada Zona $\mathrm{B}, 16$ ruang parkir pada Zona $\mathrm{C}$ dan 16 ruang parkir pada Zona D. Ruang parkir kendaraan motor memiliki kapasitas yang diperoleh sesuai perhitungan satuan ruang parkir yang dioptimasi adalah berjumlah 85 ruang parkir.

Tabel. 9. Indeks Parkir kendaraan mobil kondisi Existing Zona B

\begin{tabular}{|c|c|c|c|c|}
\hline \multirow[b]{2}{*}{$\mathrm{N}_{0}$} & \multirow[b]{2}{*}{ Tanzal } & \multicolumn{3}{|c|}{ Keadaran Mobil (Zooa B) } \\
\hline & & $\begin{array}{c}\text { Akumulasi Max } \\
\text { Kendaraan }\end{array}$ & SRP & $\begin{array}{c}\text { IP (\%) } \\
\text { (NBISRP }\end{array}$ \\
\hline 1 & $5 \cdot A p r-21$ & 21 & 18 & 117 \\
\hline 2 & $7 \cdot A p r \cdot 21$ & 30 & 18 & III \\
\hline 3 & $9 \cdot A p-21$ & 20 & 18 & III \\
\hline
\end{tabular}

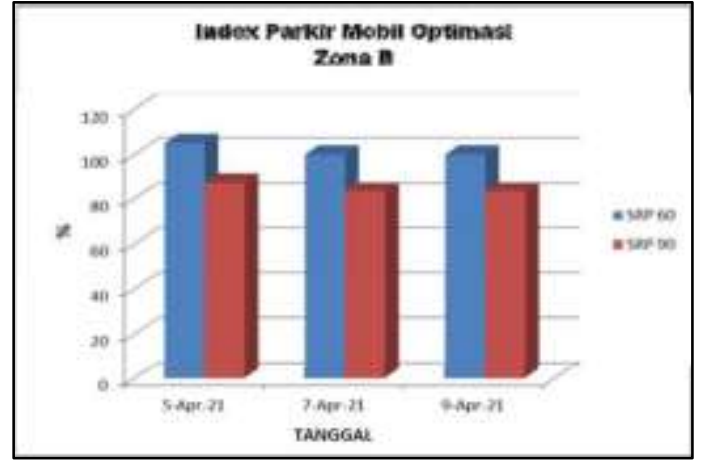

Gambar 8. Index Parkir Mobil Optimasi Zona B

Tabel. 10. Indeks Parkir kendaraan mobil kondisi Existing Zona C

\begin{tabular}{|c|c|c|c|c|}
\hline \multirow[b]{2}{*}{ No } & \multirow[b]{2}{*}{ Tangal } & \multicolumn{3}{|c|}{ Kendaraan Mobil (Zona C) } \\
\hline & & $\begin{array}{c}\text { Akumulasi Max } \\
\text { Keadaraan }\end{array}$ & SRP & $\begin{array}{c}\text { IP (\%) } \\
\text { MB!SRP }\end{array}$ \\
\hline 1 & $3-A p-21$ & 15 & II & 136 \\
\hline 2 & $7 \cdot A p-21$ & II & 11 & 100 \\
\hline 3 & $9 \cdot \mathrm{A} x-21$ & 9 & II & 82 \\
\hline
\end{tabular}

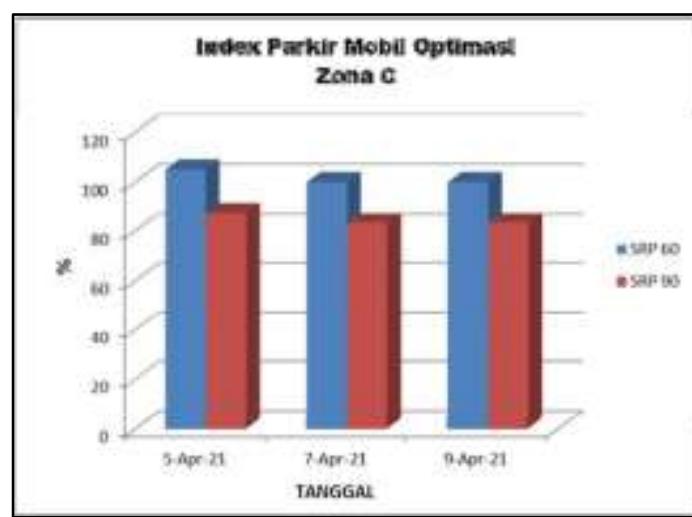

Gambar 9. Index Parkir Mobil Optimasi Zona C

Tabel. 11. Indeks Parkir mobil kondisi Existing Zona D 


\begin{tabular}{|c|c|c|c|c|}
\hline \multirow[b]{2}{*}{ No } & \multirow[b]{2}{*}{ Tanggal } & \multicolumn{3}{|c|}{ Kendaraan Mobil (Zoma D) } \\
\hline & & $\begin{array}{l}\text { Akumulasi Mlax } \\
\text { Kendaraan }\end{array}$ & SRP & $\begin{array}{l}\text { IP (\%) } \\
\text { (M) SRP }\end{array}$ \\
\hline 1 & 5-Арт-21 & 13 & II & 118 \\
\hline 2 & 7.Apt-21 & 11 & 11 & 100 \\
\hline 3 & 9-Apr-21 & 14 & 11 & 127 \\
\hline
\end{tabular}

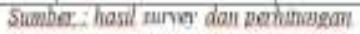

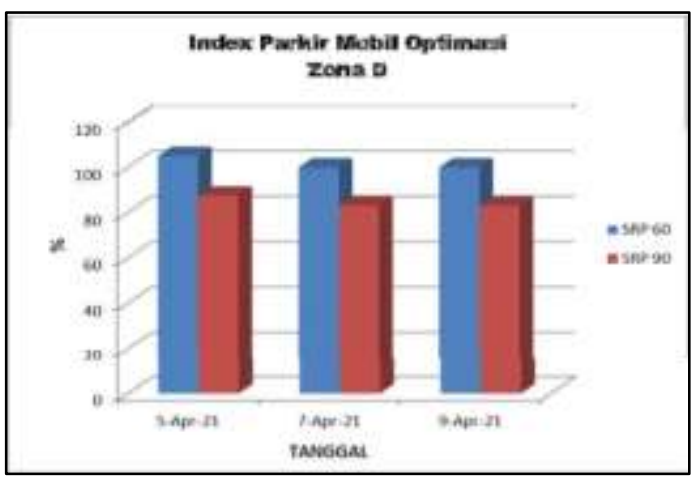

Gambar 10. Index Parkir Mobil Optimasi Zona D

Tabel. 12. Indeks Parkir kendaraan motor kondisi Existing

\begin{tabular}{|c|c|c|c|c|}
\hline \multirow[b]{2}{*}{ No } & \multirow[b]{2}{*}{ Tanggal } & \multicolumn{3}{|c|}{ Kendaraan Motor } \\
\hline & & $\begin{array}{c}\text { Akumulasi Mas } \\
\text { Kendaraan }\end{array}$ & SRP & $\begin{array}{c}\text { IP }(\%) \\
\text { (Mit SRP }\end{array}$ \\
\hline 1 & 5-Apr-21 & 73 & 64 & 114 \\
\hline 2 & $7 * A p r-21$ & 70 & 64 & 109 \\
\hline 3 & $9 \cdot$ Арг-2l & 56 & 64 & 88 \\
\hline
\end{tabular}

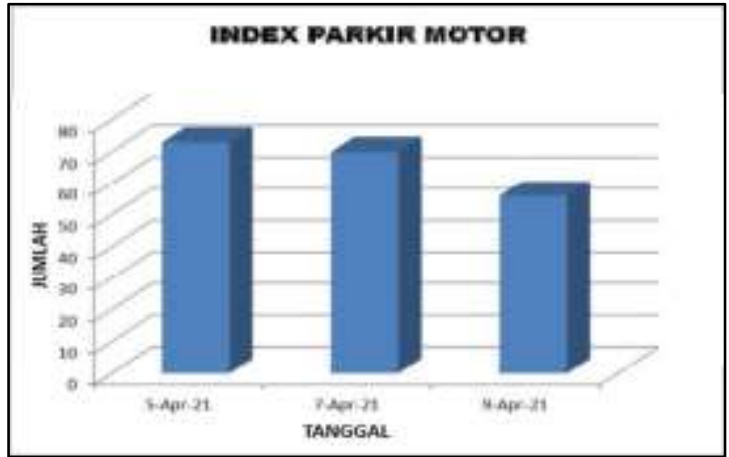

Gambar 11. Index Parkir Motor Optimasi

Tabel 9 sampai dengan Tabel 11 adalah perhitungan Indeks Parkir kondisi existing untuk kendaraan mobil di setiap Zona. Jika dilihat dari hasil perhitungan maka jumlah Indeks parkir (IP) mobil pada kondisi existing yang terjadi pada hari pertama, kedua dan ketiga rata-rata memiliki persentase diatas $100 \%$, hanya pada Zona $\mathrm{C}$ hari ketiga yang memiliki nilai IP dibawah $100 \%$. Tabel 4.12 adalah perhitungan Indeks Parkir kondisi existing untuk kendaraan motor berturut-turut selama tiga hari adalah $114 \%, 109 \%$ dan $88 \%$.

Tabel. 13. Indeks Parkir Kendaraan Mobil Optimasi pada Zona B

\begin{tabular}{|c|c|c|c|c|c|c|}
\hline \multirow[b]{2}{*}{ No } & \multirow[b]{2}{*}{ Tangeal } & \multicolumn{5}{|c|}{ Kendaraan Mobil Zoua B } \\
\hline & & $\begin{array}{l}\text { Akumulasd } \\
\text { Max } \\
\text { Kendaraan }\end{array}$ & $\begin{array}{l}\text { SRP } \\
60^{\circ}\end{array}$ & $\begin{array}{c}\text { IP }(\%) \\
\text { (MfbISRP }\end{array}$ & $\begin{array}{l}\text { SRP } \\
90^{\circ}\end{array}$ & $\begin{array}{c}\text { IP }(\%) \\
\text { (MAtSRP) }\end{array}$ \\
\hline 1 & 5.Apr-21 & 77 & 72 & 107 & 86 & 90 \\
\hline 2 & $7 * A p t=21$ & 76 & 72 & 106 & 86 & 88 \\
\hline 3 & $9-A p r-21$ & 81 & 72 & 113 & 86 & 94 \\
\hline
\end{tabular}

Tabel. 14. Indeks Parkir Kendaraan Mobil Optimasi pada Zona C

\begin{tabular}{|c|c|c|c|c|c|c|}
\hline \multirow[b]{2}{*}{ No } & \multirow[b]{2}{*}{ Tanenal } & \multicolumn{5}{|c|}{ Krendaraas Mobil Zeen C } \\
\hline & & $\begin{array}{l}\text { Akuminasi } \\
\text { Mtax } \\
\text { Kendarana }\end{array}$ & $\begin{array}{l}\text { SRP } \\
60^{\circ}\end{array}$ & $\begin{array}{c}\text { IP (\%) } \\
\text { (MItsRP) }\end{array}$ & $\begin{array}{l}\text { SRP } \\
90^{\circ}\end{array}$ & $\begin{array}{c}\text { IP (9v) } \\
\text { (MDLSRP) }\end{array}$ \\
\hline 1 & 5.Aพ*21 & 15 & 13 & 115 & 16 & 94 \\
\hline 2 & $7 \cdot A$ ax-21 & 11 & 13 & 85 & 1d & 69 \\
\hline 3 & $9 \cdot A p s=21$ & 9 & 13 & 69 & 16 & 56 \\
\hline
\end{tabular}

Tabel. 15. Indeks Parkir Kendaraan Mobil Optimasi pada Zona D

\begin{tabular}{|c|c|c|c|c|c|c|}
\hline \multirow{2}{*}{ No } & \multirow{2}{*}{ Tanggal } & \multicolumn{5}{|c|}{ Kendaraan Mobil Zona D } \\
\cline { 3 - 7 } & $\begin{array}{c}\text { Akumulasi } \\
\text { Max } \\
\text { Kendaraan }\end{array}$ & $\begin{array}{c}\text { SRP } \\
60^{\circ}\end{array}$ & $\begin{array}{c}\text { IP (\%) } \\
\text { (M)/SRP) }\end{array}$ & $\begin{array}{c}\text { SRP } \\
90^{\circ}\end{array}$ & $\begin{array}{c}\text { IP (\%) } \\
\text { (Mbl/SRP) }\end{array}$ \\
\hline 1 & 5 -Apr-21 & 13 & 13 & 100 & 16 & 81 \\
\hline 2 & $7-$ Apr-21 & 11 & 13 & 85 & 16 & 69 \\
\hline 3 & $9-$ Apr-21 & 14 & 13 & 108 & 16 & 88 \\
\hline
\end{tabular}

Pada Tabel 13 sampai dengan Tabel 15 adalah perhitungan indeks parkir optimasi pada hari pertama, kedua dan ketiga untuk kendaraan mobil di setiap zona. Pada sudut $60^{\circ}$ masih terdapat beberapa data yang memiliki Indeks diatas $100 \%$. Untuk perhitungan pada SRP sudut kemiringan $90^{\circ}$ secara keseluruhan memiliki indeks dibawah $100 \%$.

Tabel. 16. Indeks Parkir Kendaraan Sepeda Mobil Optimasi 


\begin{tabular}{|c|c|c|c|c|}
\hline \multirow{2}{*}{ No } & \multirow{2}{*}{ Tanggal } & \multicolumn{3}{|c|}{ Kendaraan Motor } \\
\cline { 3 - 5 } & $\begin{array}{c}\text { Akumulasi } \\
\text { Max } \\
\text { Kendaraan }\end{array}$ & SRP & $\begin{array}{c}\text { IP (\%) } \\
\text { (Mtr/SRP) }\end{array}$ \\
\hline 1 & $5-A p r-21$ & 73 & 85 & 86 \\
\hline 2 & $7-A p r-21$ & 70 & 85 & 82 \\
\hline 3 & $9-A p r-21$ & 56 & 85 & 66 \\
\hline
\end{tabular}

Pada Tabel 16 untuk kendaraan sepeda motor, indeks parkir memiliki nilai dibawah $100 \%$ di setiap hari survey.

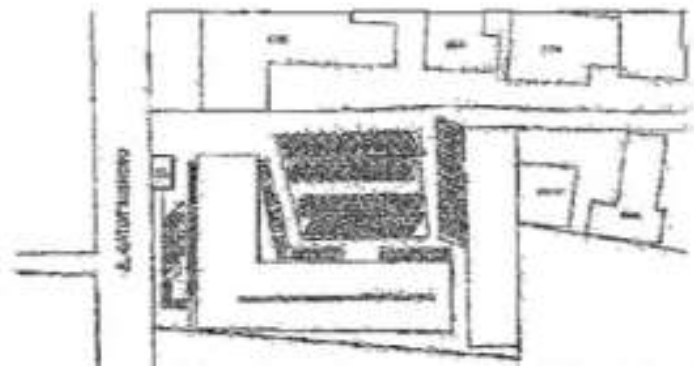

Gambar 12. Layout SRP $60^{\circ}$

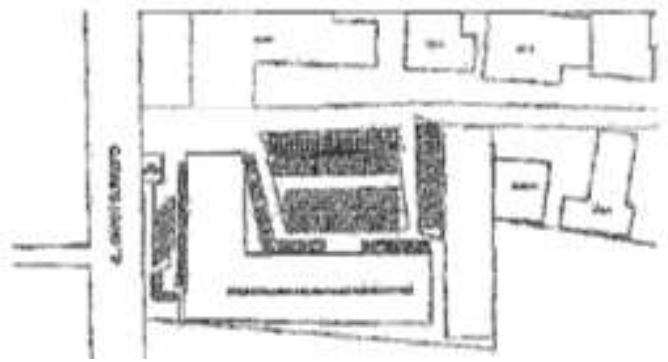

Gambar 13. Layout SRP $90^{\circ}$

Dari hasil perhitungan di atas didapatkan perbandingan antara indeks parkir kondisi existing dengan kondisi

\section{DAFTAR PUSTAKA}

[1] N. G. Arishandi, P. A. Suthanaya, and D. M. P. Wedagama, "Analisis Karakteristik Dan Kebutuhan Parkir Terminal Kargo Di Kota Denpasar," J. Spektran, vol. 5, no. 1, pp. 71-75, 2017, doi: 10.24843/spektran.2017.v05.i01.p 09.

[2] S. Kurniawan and A. Surandono, "Analisis Kebutuhan dan Penataan Ruang Parkir kendaraan," Tapak, optimasi dimana indeks parkir pada kondisi optimasi memiliki persentase lebih baik dibandingkan kondisi existing. Hal ini dikarenakan petak ruang parkir pada kondisi optimasi lebih banyak dari kondisi existing.

\section{KESIMPULAN}

Dari hasil analisa kebutuhan ruang parkir Dinas Pengelolaan Sumber Daya (PSDA) Air Provinsi Lampung yang telah dilakukan, maka dapat diambil kesimpulan antara lain: 1) Dari perhitungan data exisiting dan optimasi dengan mengambil sampel 3 hari diperoleh Tingkat pergantian parkir harian (Parking Turn Over) dimana hasil perhitungan optimasi lebih baik dari kondisi existing. Hal tersebut dikarenakan pada perhitungan kondisi optimasi menghasilkan lebih banyak ruang parkir. Hal ini berlaku pada parkir kendaraan mobil dan motor; 2) Dari hasil perhitungan Indeks parkir (IP) untuk kendaraan mobil pada kondisi optimasi memiliki hasil persentase yang lebih baik dibandingkan dengan kondisi existing pada SRP sudut kemiringan $90^{\circ}$. Hal tersebut terjadi karena ruang parkir yang menjadi lebih banyak dan efektif; dan 3) Untuk perhitungan ruang parkir pada Zona A tidak diperhitungkan sebab Zona A bukan merupakan lahan parkir melainkan jalan lalu lintas di Dinas PSDA Provinsi Lampung.

vol. 6, no. 2, pp. 127-133, 2017.

[3] F. K. J. Amahoru, Lainsamputty, "Analisis Kebutuhan Parkir Pada ACC Mall Kota Ambon," vol. 6, pp. 32-37, 2020.

[4] I. Sutapa, P. Suthanaya, and I. Suweda, "Analisis Karakteristik Dan Pemodelan Kebutuhan Parkir Pada Pusat Perbelanjaan Di Kota Denpasar," J. Ilm. Tek. Sipil, vol. 12, no. 2, 2008.

[5] A. Novier, G. Simanjutak, Y. I. 
Wicaksono, and A. K. Indriastuti, "Analisis Kebutuhan Ruang Parkir Paragon Mall Semarang," Hal. Tek. SIPIL, vol. 4, no. 4, pp. 141-154, 2015.

[6] A. M. Yunita, A. E. L. K. Roky, and H. R. Andi, "Analisis Kebutuhan Lahan Parkir Di Rumah Sakit Umum Daerah Prof. Dr. W.Z. Johannes Kupang," J. Tek. Sipil, vol. 1, no. 4, pp. 87-100, 2012.

[7] P. "Analisis Karakteristik Dan Kebutuhan Ruang Parkir Pada Pusat Perbelanjaan Di Kabupaten Badung," J. Ilm. Tek. Sipil, vol. 14, no. 1, 2010.

[8] R. Anwar, "Analisis Model Kebutuhan Parkir Pada Bangunan Perdagangan Di Kota Banjarmasin," vol. 6, no. 2, pp. 5763, 2005. 